\title{
Towards a European Framework for Community Engagement in Higher Education
}

\author{
Thomas Farnell and Bojana Ćulum Ilić
}

\begin{abstract}
This chapter presents some of the key conclusions of the project 'TEFCE - Towards a European Framework for Community Engagement of Higher Education'. The project has developed an innovative "toolbox" that supports universities and policymakers in fostering community engagement. It provides a meaningful assessment of an institution's level of community engagement, and thus opens a platform to discuss how to improve institutional community engagement performance.
\end{abstract}

\section{Keywords}

university-community engagement - engagement in higher education - TEFCE Toolbox - critical approach to assessing community engagement in higher education

Over the past several decades, increased attention has been paid to the impact of higher education on society. However, the focus of most third mission policies and practice has been overwhelmingly on the economic significance of universities - from the commercialisation of research, to university-business cooperation and to the labour market relevance of graduate skills. Today, however, there is arguably a steady shift in policy towards the broader societal impact of universities, and there is increasing recognition internationally of universities' social responsibility and the role they play in delivering public benefits. At the international level, this is reflected in the current debate on the roles of universities in meeting the UN's 2030 Agenda for Sustainable Development. At the European level, this is reflected by the increasing prominence of Responsible Research and Innovation since 2011 and the emergence of the topic of community engagement for the first time in EU policy on higher

(C) THOMAS FARNELL AND BOJANA ĆULUM ILIĆ, 2021 | DOI: 10.1163/9789004459076_021

This is an open access chapter distributed under the terms of the CC BY-NC 4.0 License. 
education within the European Commission's Renewed Agenda for Higher Education (2017).

As a response to this emerging agenda in Europe, an EU-funded project was developed entitled Towards a European Framework for Community Engagement in Higher Education (TEFCE). 'Community engagement', as defined in the TEFCE project, refers to the development of mutually beneficial partnerships between universities and their external communities, in order to address societal needs - and is, thus, a fundamental aspect of the social responsibility of higher education. In this chapter, we will present the initial results of the TEFCE project and its potential impact of supporting the community engagement agenda in Europe.

About the TEFCE Project

The TEFCE project, coordinated by Technische Universität Dresden (Germany) and the Institute for the Development of Education (Croatia) involves twelve partners from eight EU Member States, ${ }^{2}$ and is funded through the European Commission Erasmus+ programme. The objective of the TEFCE project is to develop innovative and feasible policy tools at the university and European levels for supporting, monitoring and assessing the community engagement of universities. In order to achieve this, the TEFCE project consists of four work packages:

- Mapping and critical synthesis of existing research, policy and practice on community engagement

- Developing an innovative toolbox (including guidance, assessment and peer-learning) for higher education institutions on community engagement

- Piloting the community engagement toolbox at selected European higher education institutions

- Assessing the feasibility of a European accountability tools for community engagement

The mapping and critical synthesis of existing research, policy and practice on community engagement ${ }^{3}$ provided the project experts with additional insights into the definitions, approaches and challenges to community engagement, as well as into the difficulties of developing effective accountability tools in higher education. The literature analysis proved that policy priorities in higher education focus on excellence and global league tables, and do not encourage community engagement. Furthermore, the analysis demonstrated that there is no 'one-size-fits-all' approach to community engagement - it is 
always context-specific. Different places have different histories of university engagement, different cultures and different communities. The value of different forms of community engagement also varies per academic discipline. It is, therefore, important that academic staff retain the autonomy to determine how best to organise their community engagement activities. And to make a central point, the analysis manifested that community engagement is resistant to being measured. In the context of management systems where 'what can be measured matters', community engagement is not immediately available for codification and measurement.

This led the TEFCE team to map existing tools for assessing community engagement in higher education, to analyse the value of such tools and to consider what alternative approaches could be adopted to create an innovative European tool for community engagement. Among the tools analysed by Farnell and Šćukanec (2018) were a number of self-assessment frameworks from the U.S. (e.g. the Holland matrix, the Campus Compact Indicators of Engagement and the Furco rubric) and a number of external assessment framework, such as the AUCEA Benchmarking University Community Engagement Pilot Project (Australia) and the Carnegie Elective Classification for Community Engagement. The analysis done proved that the previous attempts to 'quantify' community engagement have been unsuccessful. For example, in 2011, the European Indicators and Ranking Methodology for University Third Mission $\left(\mathrm{E}_{3} \mathrm{M}\right)$ were developed through a project co-funded by the European Commission, with the objective to develop standard quantitative indicators for third mission activities of universities. Despite having developed a comprehensive database with 98 indicators, their implementation proved impracticable and the developed methodology has not been used after the project's completion. In addition, the analysis demonstrated that institutional self-assessment tools for community engagement can also provide an alternative approach to assessment, although they have their limits. Dozens of tools, primarily in the U.S., Australia and the UK, exist to help higher education institutions reflect upon the extent to which they are community-engaged.

The disadvantages and limits of the existing self-assessment tools analysed are that they focus on the process of community engagement, rather than on outcomes or impact. They are more 'top-down' than 'bottom-up', and do not provide a clear platform for including community perspectives in the process.

The key question faced by the TEFCE project was, therefore: is there any gap within the existing attempts to develop tools for community engagement in higher education, and is there a space for the TEFCE project to develop an innovative approach? If so, what form of tool should be developed, and how to balance internal versus external assessment, and qualitative versus 
quantitative approaches? The following sections describe the main result of the TEFCE project: the development of an innovative Toolbox for Community Engagement in Higher Education (Farnell et al., 2020a).

\section{How to Create an Innovative and Critical Approach to Assessing Community Engagement in Higher Education?}

The first foundation of the TEFCE approach is that what has been missing in previous tools has been the consideration of authenticity of community engagement, in terms of how mutually beneficial the partnerships with communities are. As a concept and set of actions, community engagement ranges from one-dimensional to multifaceted, from superficial to deep and embedded, from transactional to transformational. The TEFCE project team, therefore, referenced literature (mapped in Ćulum, 2018) that adopts a critical approach to defining community engagement, differentiating authentic and embedded engagement to approaches that are more superficial (e.g. Benneworth, 2013; Bowen et al., 2010; Clayton et al., 2010; Hoyt, 2011; Enos \& Morton, 2003; Hall et al., 2011; Himmelman, 2001) and eventually synthesised the literature into an overarching epistemological reference framework, as provided in Table 20.1.

The 'ethos' category in the framework above refers to community engagement being built into university core knowledge processes, thereby ensuring effective and, ultimately, sustainable university-community engagement. The 'relationships' category describes positioning of the community representatives, meaning, ultimately, their integration into the life of the university and participating in university life by shaping university decision-making. 'Mutuality' refers to the university planning and organising their engagement activities to maximise the benefits they bring both to university and community. 'Directionality' refers to the level of community partners' involvement as equal partners in various activities, in ways that allow their voices to meaningfully affect activity choices. Finally, 'endowment' refers to community partners being repositioned within power structures to be better positioned to demand their own interests.

Based upon the framework, descriptors of the different levels of community engagement for each of the Toolbox's core dimensions have been developed, leaning primarily on analysing community engagement in higher education from the perspective of power and reciprocity (Himmelman, 2001), arguing that the nuances of reciprocity versus exploitation make those vital variations in university-community engagement. 


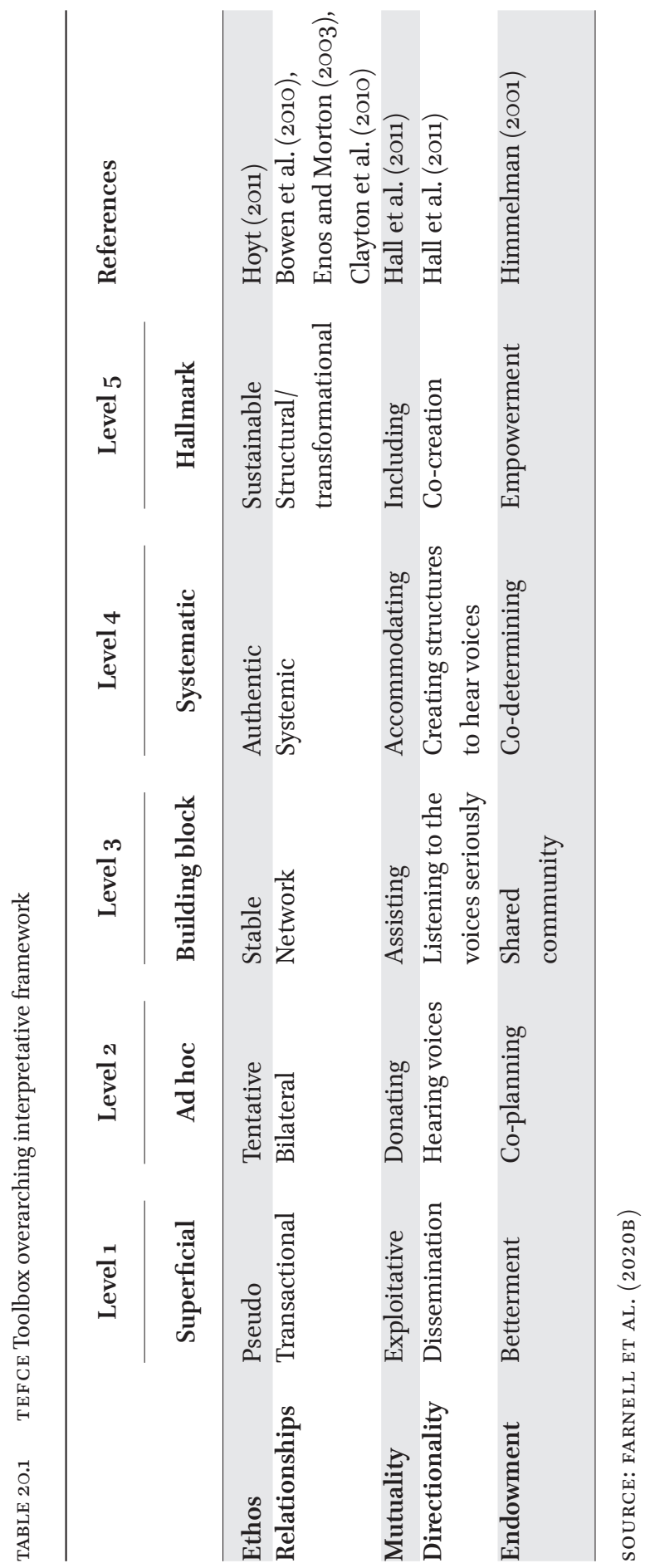


In considering methods for the TEFCE Toolbox, the TEFCE project adopted a critical approach to narrow New Public Management (NPM) approaches to performance assessment. Such an approach is highly rigid and undermines the encouraging and rewarding of universities for responding constructively to societal needs (Benneworth et al., 2018).

In proposing a new framework for community engagement in the European Higher Education Area (EHEA), the TEFCE project places community engagement into its wider higher education context, understanding the interrelatedness of constraints and barriers that it faces, and tuning a framework to assist universities in seeking to address those constraints and barriers. The TEFCE project is examining how to balance internal and external assessments, qualitative and quantitative assessments, as well as how to develop a multidimensional, customisable and bottom-up approach to assessment. Rather than being a measurement and ranking exercise, TEFCE Toolbox aims to foster a learning journey for universities towards transformational forms of engagement. The toolbox bases itself on literature that adopts a critical approach to defining community engagement, and its main principles are: (1) commitment to authentic, mutually beneficial community engagement; (2) empowerment of individual actors within and outside university; (3) combined top-down and bottom-up approaches and (4) collaborative learning, rather than comparison of competitive performance.

The TEFCE Toolbox is defined as both a reference tool to understand the dimensions of community engagement in a university context, and a framework for universities to determine how well they perform according to each dimension, as well as where they can improve.

Based on extensive literature reviews, the TEFCE Toolbox is structured around seven core thematic dimensions of community engagement, followed by the 21 sub-dimensions, as illustrated in Table 20.2.

As this range of dimensions suggests, community engagement can encompass a broad range of activities that includes cooperation with the community. However, returning to the key principle of authenticity of engagement, as described above, the TEFCE project differentiates between levels of community engagement. The levels of engagement defined for each sub-dimension of the Toolbox reflect the fact that some community engagement activities are more genuine, and mutually beneficial, than others. 


\section{Dimension I. Teaching and learning}

I.1 The university has study programmes that include content about societal needs that are specific to the university's context and its external communities

I.2 The university has study programmes that include a community-based learning component for students

I.3 The university has study programmes that are created, reviewed or evaluated in consultation/cooperation with external community representatives

I.4 The university facilitates the participation of community representatives in the teaching and learning process in some study programmes (in a curricular or extracurricular context)

\section{Dimension II. Research}

II.1 The university has research projects about the societal needs of external communities

II.2 The university has collaborative/participatory research projects, which are implemented in cooperation with community groups

\section{Dimension III. Service/knowledge exchange}

III.1 University staff use their knowledge to contribute to public debates, culture and politics related to matters of interest to the community

III.2 University staff use their knowledge to support collective organisations representing professional/community/business interests

III.3 The university contributes to building the capacity of community groups (advocacy groups or groups involved in social enterprise, entrepreneurship and innovation)

III.4 The university visibly creates positive impacts through its community engagement activities (public policy, upskilling, capacity building, economic impact, etc.) 


\section{Dimension IV. Students}

IV.1 Students deliver their own community engagement activities through student organisations or initiatives

IV.2 University facilitates matchmaking (e.g. volunteering, NGO employment) between community groups and students through extra-curricular activities

\section{Dimension V. Management (communication and partnerships)}

V.1 The university has long-standing/recurrent mutually-beneficial partnerships with community groups

V.2 The university makes the results of its research, teaching and other activities open and accessible to the public

V.3 The university has jointly-owned, shared, managed or community accessible facilities/services together with community groups

\section{Dimension VI. Management (policies and support structures)}

VI.1 University policies for staff development processes (e.g. recruitment, tenure, promotion) include community engagement activities as criteria

VI.2 The university recognises and acknowledges (e.g. via awards) achievements in community engagement by staff, students and key partners

VI.3 The university has a support structure (e.g. high-level committee, outreach office and/or staff) that embeds and recognises university-community engagement activities

VI.4 The university has a clear mission, strategy, leadership and (funding) instruments that promote community engagement

\section{Dimension VIII. Supportive peers}

VII.1 Academic staff are supportive of their university undertaking communityengaged learning

VII.2 Academic influencers/mavens are active in advancing community-engaged teaching/learning and research 
The TEFCE Toolbox provided the University of Rijeka (Croatia - hereafter UNIRI), as one of the TEFCE partner institution piloting the Toolbox, with the opportunity to reflect, in a structured way, on how community-engaged their staff and students, as well as policies, study programmes and research projects are. The qualitative and participatory process of applying the Toolbox itself was carried out through a series of steps defined by the TEFCE project/Toolbox: (I) Quick scan - initial discussion by a university/community team of 20 people on the type and extent of current community engagement activities carried out at the university level; (II) Evidence - collecting case studies of community-engaged practitioners throughout the university; (III) Mapping TEFCE Toolbox matrix was used to map the level of community engagement of the university and to identify good practices, resulting in a background institutional report; (IV) Self-reflection - open and participative discussions among university management, staff, students and the community organisations' representatives on strengths and areas of improvement; and (V) Synthesis - writing an institutional report aiming to promote good practices and their impact, as well as critical self-reflections for planning improvements to universitycommunity engagement.

During a five-week long period, the UNIRI piloting team collected 50 community-engaged practices that were analysed in the institutional report using a TEFCE framework of seven core dimensions and 21 sub-dimensions. Leaning on the TEFCE Toolbox interpretative framework, the background institutional report served as a platform for critical reflection on the following: the authenticity of engagement, type of social needs addressed, the type of communities engaged with, how outspread engaged practices are considering disciplinary provenance, and how (institutionally) sustainable those practices are.

During a subsequent two-day study visit that followed, a series of structured participatory dialogues took place between four external experts and university management (rector), academics, students and community representatives. During the UNIRI piloting visit, an additional analytical framework, developed by the TEFCE project called the 'SLIPDOT analysis', was also used and piloted for the first time. Similar to the well-known SwOT analysis, the SLIPDOT analysis of community-engagement at UNIRI allowed for experts' critical reflection and discussion on recognised areas of strengths, those of low intensity and potential for development (instead of 'weaknesses'), and of opportunities and threats in both the national and European contexts. The experts' in-depth analysis was presented to the piloting team at UNIRI and used as a base for action planning on how to further improve community engagement at UNIRI. 
Within the project, the TEFCE Toolbox was piloted by four universities and their local partners (Technical University of Dresden, Germany; Technological University Dublin, Ireland; the University of Rijeka, Croatia; University of Twente, the Netherlands). The piloting of the Toolbox allowed for both a 'testing' of the current framework and for its further improvements. Piloting the Toolbox in four different contexts yielded four main conclusions. Firstly, a broad range of community engagement activities can be captured using the Toolbox, as it is not restrictive or exclusive in its categorisation of what 'counts' as engagement. The value in mapping diverse activities is because this is often underappreciated in institutions and, then, can be neglected as a result. Secondly, the process is context-specific, meaning that institutions can make sense of the dimensions and sub-dimensions in different ways, in light of their contexts, ultimately allowing institutions to take ownership of the process. Thirdly, the Toolbox process is participative and allows for participants - including staff, students and community' representatives - to have a meaningful say in the process and to influence the conclusions of the assessment. And lastly, the Toolbox approach does not allow for direct comparability between institutions, because it is framed as an institutional learning journey. Instead, the instrument seeks to create actionable knowledge to improve community engagement in the institution by empowering participants and acknowledging good work. The improvement mechanisms create an understanding of potential for improvement, but also create the conditions for improvement by mobilising potential participants.

The TEFCE project will continue to explore how the Toolbox could be further improved until the end of 2020. The project will also explore future scenarios for making the use of the Toolbox more widespread and sustainable in the future, through 'bottom-up' initiatives of engaged universities and/or through ensuring 'top-down' support for such a framework at the policy level. Ultimately, the ambition is for the TEFCE Toolbox to serve as a European framework for community engagement in higher education, thus supporting the broader policy agenda of social responsibility in higher education.

\section{Acknowledgements}

This chapter results from the project Towards a European Framework for Community Engagement of Higher Education funded by the European Commission's Erasmus+ Programme, Key Action 3, Forward Looking Cooperation projects 
(grant agreement: 590200-EPP-1-2O17-1-DE-EPPKA3-PI-FORWARD) and is cofinanced by the Croatian Government's Office for Cooperation with NG Os. The views expressed in this publication are the sole responsibility of the authors and can in no way be taken to reflect the views of the project's funding institutions. The funding institutions cannot be held responsible for any use which may be made of the information contained therein.

\section{Notes}

1 See www.tefce.eu

2 The other TEFCE consortium members are: University of Twente (Centre for Higher Education Policy Studies), University of Ghent (Centre for Higher Education Governance Ghent), Technological University of Dublin, University of Rijeka and the cities of Dresden, Dublin, Enschede and Rijeka, as well as the European Consortium of Innovative Universities, the Global University Network for Innovation (represented by the Catalan Association of Public Universities) and the Public Policy and Management Institute from Lithuania. TEFCE is a three-year long project, lasting from 2018 till the end of 2020.

3 The results of the first phase of the TEFCE project was the publication Mapping and Critical Synthesis of Current State-of-the-Art on Community Engagement in Higher Education (Benneworth et al., 2018), available at https://www.tefce.eu/publications

\section{References}

Benneworth, P. S. (2013). The engaged university in practice? In P. S. Benneworth (Ed.), University engagement with socially excluded communities. Springer.

Benneworth, P. S. (2018). Definitions, approaches and challenges to community engagement. In P. S. Benneworth et al. (Eds.), Mapping and critical synthesis of current state-of-the-art on community engagement in higher education. Institute for the Development of Education.

Benneworth, P. S., Ćulum, B., Farnell, T., Kaiser, F., Seeber, M., Scukanec, N., Vossensteyn, H., \& Westerheijden, D. F. (2018). Mapping and critical synthesis of current state-ofthe-art on community engagement in higher education. Institute for the Development of Education.

Benneworth, P. S., Kaiser, F., Vossensteyn, H., \& Westerheijden, D. (2018). Critical approaches to developing effective accountability tools in higher education. In P. S. Benneworth et al. (Eds.), Mapping and critical synthesis of current state-of-theart on community engagement in higher education. Institute for the Development of Education. 
Bowen, F., Newenham-Kahindi, A., \& Herremans, I. (2010). When suits meet roots: The antecedents and consequences of community engagement strategy.Journal of Business Ethics, 95, 297-318.

Clayton, P. H., Bringle, R. G., Senor, B., Huq, J., \& Morrison, M. (2010). Differentiating and assessing relationships in service-learning and civic engagement: Exploitative, transactional, or transformational. Michigan Journal of Community Service Learning, $16(2), 5^{-21}$.

Ćulum, B. (2018). Literature review: Dimensions and current practices of community engagement Bojana Ćulum. In P. S. Benneworth et al. (Eds.), Mapping and critical synthesis of current state-of-the-art on community engagement in higher education. Institute for the Development of Education.

Enos, S., \& Morton, K. (2003). Developing a theory and practice of community-campus partnerships. In B. Jacoby (Ed.), Building partnerships for service-learning (pp. 20-41). Jossey-Bass.

Farnell, T., Benneworth, P., Ćulum Ilić, B., Seeber, M., \& Šćukanec Schmidt, N. (2O2Oa). Toolbox for community engagement in higher education. Institute for the Development of Education.

Farnell, T., Ćulum Ilić, B., Dusi, D., O’Brien, E., Šćukanec Schmidt, N., Veidemane, A., \& Westerheijden, D. (2020b). Building and piloting the TEFCE toolbox for community engagement in higher education. Institute for the Development of Education.

Farnell, T., \& Šćukanec, N. (2018). Mapping existing tools for assessing community engagement in higher education. In P. S. Benneworth et al. (Eds.), Mapping and critical synthesis of current state-of-the-art on community engagement in higher education. Institute for the Development of Education.

Hall, P. V., Smith, J., Kay, A., Downing, R., MacPherson, I., \& McKitrick, A. (2011). Introduction: Learning from the social economy community-university research partnerships. In P. V. Hall \& I. MacPherson (Eds.), Community-university research partnerships: Reflections on the Canadian social economy experience (pp. 1-26). The University of Victoria.

Himmelman, A. T. (2001). On coalitions and the transformation of power relations: Collaborative betterment and collaborative empowerment. American Journal of Community Psychology, 29(2), 277-284.

Hoyt, L. (2011). Sustained city-campus engagement: Developing an epistemology for our time. In J. Saltmarsh \& M. Hartley (Eds.), 'To serve a larger purpose': Engagement for democracy and the transformation of higher education (pp. 265-288). Temple University Press. 